\title{
Abhandlung
}

Jeanette C. Fincke* and Mathieu Ossendrijver*

\section{BM 46550 - a Late Babylonian Mathematical Tablet with Computations of Reciprocal Numbers}

DOI 10.1515/za-2016-0016

\begin{abstract}
The mathematical tablet BM 46550 offers the first evidence that a method for computing and verifying reciprocal numbers, thus far attested only in the Old Babylonian era, continued to be applied, in a similar manner, in the Neo- or Late Babylonian era. At least part of the tablet was computed on the spot, some of the columns being written from bottom to top. The mathematical tables are accompanied by an unusual drawing, apparently unrelated to the text.
\end{abstract}

BM $46550(1881-8-30,16)$ belongs to the Babylon-Sippar collection of the British Museum. ${ }^{1}$ Unambiguous information about its provenance is not available and it lacks an invocation or a colophon that might have revealed where it was written. Some useful inferences can be derived from the available records about the arrival of tablets in the British Museum. The collection $1881-8-30^{2}$, which arrived on 30 August 1881, consisted of five cases with tablets and other objects from the sites of Dailem (ancient Dilbat), Babylon and Ibrahim al-Khalil (ancient Borsippa). None of these sites can be definitely excluded as the findspot of BM 46550. The mathematical content speaks against Dailem and in favor of Babylon, a known center of scholarship where dozens of Late Babylonian mathematical tablets were found. On the other hand, the tablet's landscape format is unusual for Babylon, which raises the

1 J. C. Fincke identifed BM 46550 among unpublished Babylonian tablets in the British Museum and recognized the mathematical nature of its content. During a visit to the study room of the Middle East Department of the British Museum in February 2014, J. C. Fincke showed the tablet to M. Ossendrijver, who then identified the content, after which the idea emerged to publish the tablet together. J.C. Fincke produced the copy and analysed the damage of the tablet's surface and the drawing, while M. Ossendrijver elaborated on the contents of the tablet. We express our thanks to Walther Sallaberger for reading this paper and suggesting several improvements.

2 See Reade in: Leichty (1986, xxxi-xxxii).

*Corresponding authors: Jeanette C. Fincke, School of Oriental and African Studies (London), jeanette.fincke@ori.uni-heidelberg.de Mathieu Ossendrijver, Humboldt University/Excellence Cluster TOPOI (Berlin), mathieu.ossendrijver@hu-berlin.de possibility that it originates from Borsippa. ${ }^{3}$ Only a rough indication of the date can be given. Most tablets of the Babylon-Sippar collection date between 700 and 100 BCE and the same can be assumed for BM 46550. On paleographic grounds, in particular the pre-Seleucid shape of the numeral 9 (see below), a Seleucid or Parthian date is unlikely. Hence the tablet most likely dates from the Neo-Babylonian or Achaemenid era (ca. 700-330 BCE). ${ }^{4}$

\section{The tablet}

The tablet measures $108.5 \times 85 \times 31 \mathrm{~mm}$ and is nearly intact. It is colored black, presumably because of burning or baking. Most of the tablet's surface shows some kind of damage: at the lower edge reaching into the upper part of reverse, two tongue-like plain cuts carve evenly into the clay tablet. Another similar but flatter cut can be seen at the left side of the tablet's upper edge. This damage was most likely caused by a pickaxe or a similar tool when the tablet was excavated. On the obverse one can see

3 As mentioned by Reade, at least one Neo-Babylonian tablet with a nearby accession number, BM $46543(1881-8-30,9)$, is demonstrably from Borsippa. This tablet is a copy of an inscription by Hammurabi with a colophon mentioning Ezida, the temple of Nabû in Borsippa (LIH 59).

4 The earliest datable and closest parallels of BM 46550 are two tablets from Uruk, SpTU 4, 176 and SpTU 5, 316, to be discussed further below. Using archaeological and archival criteria they have been dated to $415 \pm 30 \mathrm{BCE}$, in the Achaemenid era (Clancier 2009, 58-59. 404). 
segments of irregular shape and various sizes where the topmost layer of the surface is removed. Although these traces cover quite a large area, they cause no damage to the cuneiform signs. It is conceivable that the contact with the surrounding earth, be it through mechanical or chemical reaction, could have caused the surface to chip off.

\section{Trace fossils}

At the upper right part of the obverse a kind of trail consisting of imbricate and crisscrossing linear indentions can be seen that trench deeper into the tablet and damage the cuneiform signs. A similar path can be seen in the area between the tablet's reverse and upper edge. On the reverse, similar random curved grooves that follow the same direction can be seen covering larger areas; most of these traces are much flatter, only a few carve deeper into the clay. Still, they seem to have the same cause as the trails or paths, and they damage the cuneiform signs. M.-C. Ludwig $(2009,12-14)$ was the first to describe similar traces characterised by imbricate and crisscrossing linear indentions that follow the same direction in her study on the literary tablets from Ur. According to her research, hypogeal insects that dig burrows through the earth cause these "trace fossils" on the objects while buried in the ground. Some of these burrows passed by the cuneiform tablets more or less closely, others lead through them leaving behind a transfixion of the tablet. One type of insect that could cause such damage are the nymphs of cicadas, which have strong front legs for digging. The adult male cicadas produce a distinct sound, a characteristic "singing". Since the nymphs feed on sap from the roots of various species of trees, including cypress, willow, ash and maple, while the adult cicadas suck sap from the plants, tablets with these distinct traces have most likely been lying in limited areas. Thus, future studies in trace fossiles could help to narrow down the possible find spot of BM 46550 to one of the mentioned sites of Dailem (Dilbat), Babylon and Ibrahim al-Khalil (Borsippa).

\section{The drawing}

On the lower part of obverse, reaching onto the lower edge, a drawing is incised into the tablet's surface in the empty space between the first two columns of numbers. The image is damaged by trace fossils and could therefore be incomplete. One can see a long and much curved til- de-like line with a mirror line below it, beginning slightly towards the right of the first line. At the left part, both curved lines are connected inside the parting waves by two straight lines that lead to the right and meet in an angle of almost $90^{\circ}$. This image resembles a fish with an open mouth facing left or a bird flying to the right.

Simple images of incised fishes and birds can be seen on some Neo-Babylonian administrative tablets from Babylon and Sippar, where they seem to be a marker for the subject of the tablets or for a certain archive. These fishes, however, are drawn facing right and with their mouth shut, ${ }^{5}$ and the birds are depicted as standing on the ground facing left. ${ }^{6}$ Incised drawings on clay tablets are rare, but can be found already among the earliest cuneiform tablets known so far. School texts or rather student copies from Fara (Šuruppak) and Tell Abū Șalābīkh (late fourth or early third millennium BCE) occasionally show incised images of a geometrical nature ${ }^{7}$ on their reverse; some depict humans or animals as incisions. ${ }^{8}$ Since the figure incised on our mathematical tablet clearly shows an animal, the following overview of incised images on cuneiform tablets will ignore depictions of humans or anthropomorphic gods and objects. ${ }^{9}$ Two tablets with incised animals from the Hittite capital Hattuša roughly dated to the $14^{\text {th }}$ and $13^{\text {th }}$ century BCE are library tablets rather than school tablets or student copies. ${ }^{10}$ Five Middle Babylonian tablets from the private archive of Itti-Ezida-lummir in Babylon dating to the reigns of Adad-šuma-ușur and Melišipak (late $11^{\text {th }}$ to early $12^{\text {th }}$ century BCE) depict incised scenes with animals; to date, only the very lively scene with a lion attacking a wild boar giving proof

5 See, e.g., Pedersén (2005, 189, fig. 77, 191): N8 no. 27 (a fish), a tablet found in the Ištar temple dating to the Neo-Babylonian period. See also Gesche (2001, 208-209): BM 72072 (two fishes).

6 See, e.g., CT 55, 712 and 713 and CT 56, 93.

7 For Fara see Deimel $(1923,37)$ no. 39 (VAT 12606) col. x (a kind of flower or rosette), p. 52, no. 55 (VAT 9112) cols. xii and xiii (geometrical), p. 71, pl. 8, 76 (VAT 9130; waved double-lines). For Tell Abū Șalābīkh see Biggs (1974, 30-31) 2.47 and an unnumbered fragment, pl. 27, 47 (AbS T 222) reverse (for this see already Biggs [1966], 83, 3), pl. 34, 60 reverse and p. 130 no. 282 reverse (all rather complex geometrical designs).

8 For Fara see, e.g., Deimel (1923, 63, 62): VAT 12526 reverse (the torso of a man).

9 Thus, the incised drawings on divinatory or ritual tablets from Hattuša, Assyria and Babylonia are neglected. For an overview on incised drawings on Assyrian and Babylonian ritual tablets mainly from the first millennium BCE see Finkel (2011).

10 KUB 28, 4 (Bo. 446: lion on a tablet with the Hattian-Hittite bilingual of the myth of the moon [CTH 727]) and VBoT 87 (Sayce 16: heads of animals on an inventory tablet of the house of seals [CTH 503]). 
of a very sophisticated illustrator has been published. ${ }^{11}$ Since these tablets have only these drawings but no text they most probably also belong to the sphere of school education. A few school tablets from the first millennium BCE found in Babylon have incised figures on the reverse of tablets; these, however, depict very simple figures such as a fish or a star. ${ }^{12}$ As such they are related to the plain incised drawings and markings of geometrical (crosses, squares, stars, spades and pots) or figural nature (birds, plants, standards of gods, winged discs or weapons) that can be found on administrative tablets from the Ebabbar temple in Sippar dating to the sixth century BCE; these images are usually connected to the subject matter of the tablets. ${ }^{13}$ In Babylonia, animals have not only been incised on tablets that most likely belong to the sphere of school education or administration. Two library tablets with reference to micro-zodiacal signs and their associ- ated cities, temples, stones and plants show the images of constellations with captions such as the Maiden (MUL. AB.Sín; Virgo), the Dragon-snake (MUL.MUš; Hydra), the Raven (MUL.UGA.MUŠEN; Corvus) and the Lion (MUL.UR. GU.LA; Leo). ${ }^{14}$

\section{Transliteration}

For the benefit of the reader the following transliteration is accompanied by an explanatory header and, to the right of the vertical ruling, two columns with modern representations of the sexagesimal numbers in cols. $i$ and ii. There are several instances of partly erased signs, which are indicated by asterisks $\left({ }^{\star}\right)$.
11 See Pedersén (2005, 95, 97-101): M8 nos. 1 (lion, wild boar), 3 (wagon and horses), 96 ([wagon] and two horses), 98 (animals) and 99 (image not described). For a photograph of the image of no. 1 see p. 93, 43.

12 See above footnotes 5 and 6.

13 See, e.g., Appendix 2 by Jursa in: Zawadzki/Jursa (2001, 357-363, esp. the table pp. 359-362).
14 VAT 7851 and VAT 7847+AO 6448; see Weidner (1967, 12-40), pl. 1-10. 


\begin{tabular}{|c|c|c|c|c|c|}
\hline & Column i: s & $i i: \bar{s}$ & iii: $\bar{f}$ & $s$ & $\bar{s}$ \\
\hline \multicolumn{6}{|c|}{ Obverse } \\
\hline \multirow[t]{4}{*}{1} & ${ }^{\prime} 1^{\prime} \cdot 1.2 .6 .33 .45$ & 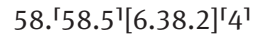 & 2 & $5^{6} \cdot 30^{8}$ & $12^{6} \cdot 2^{8}$ \\
\hline & 2.2.4.13.4.30 (error) & $29.2^{\ulcorner} 9^{\top} .2^{\top} 8.19 .12^{\top}$ & 2 & $5^{6} \cdot 30^{7}$ & $12^{6} \cdot 2^{7}$ \\
\hline & 4.4.8.26.15 & 14.44 .44 .9 .36 & 2 & $5^{6} \cdot 30^{6}$ & $12^{6} \cdot 2^{6}$ \\
\hline & 8.8 .16 .52 .30 * & 7.22 .22 .4 .48 & 2 & $56 \cdot 30^{5}$ & $12^{6 \cdot 2^{5}}$ \\
\hline \multirow[t]{5}{*}{5} & 16.16 .33 .45 & 3.41 .11 .2 .24 & 2 & $5^{6} \cdot 30^{4}$ & $12^{6} \cdot 2^{4}$ \\
\hline & $32 ! \cdot 33.7 .30$ & 1.50 .35 .31 .12 & 2 & $5^{6} \cdot 30^{3}$ & $12^{6} \cdot 2^{3}$ \\
\hline & $1.5 *^{\star \mp} 6.1^{1} 5$ & 55.17 .45 .36 & 2 & $5^{6} \cdot 30^{2}$ & $12^{6} \cdot 2^{2}$ \\
\hline & $3.10 .1^{\top} 2.30^{\top}$ (error) & $\star 27.38 .52 .48$ & 2 & $5^{6 \cdot 30}$ & $12^{6 \cdot 2}$ \\
\hline & 4.20 .25 & $13.49 .26 .2^{\Gamma} 4^{1}$ & 12 & $5^{6}$ & $12^{6}$ \\
\hline \multirow[t]{5}{*}{10} & 52.5 & 1.9.7.1 $1^{1} 2^{\star *}$ & 12 & $5^{5}$ & $12^{5}$ \\
\hline & 10.25 & 5.45 .36 & 12 & $5^{4}$ & $12^{4}$ \\
\hline & 2.5 & 28.48 & 12 & $5^{3}$ & $12^{3}$ \\
\hline & 25 & 2.24 & 12 & $5^{2}$ & $12^{2}$ \\
\hline & 5 & 12 & 12 & 5 & 12 \\
\hline 15 & 1 & $\langle 1\rangle$ & ${ }^{\mathrm{I}} \mathrm{X}^{1}$ & 1 & 1 \\
\hline \multicolumn{6}{|c|}{ Reverse } \\
\hline \multirow[t]{4}{*}{1} & $58 . .^{\Gamma}[8.56 .38 .24$ & 1.1.2].6.33.45 & ${ }^{\top} 30^{1}$ & $2^{14} \cdot 6^{6}$ & $30^{14} \cdot 10^{6}$ \\
\hline & $29 .{ }^{\top} 29^{1} \cdot{ }^{\prime}[2]^{\top} 8^{\top} \cdot[19.12$ & $2.2] .{ }^{\top} 4^{\top} \cdot 13 .{ }^{\star} 7.30$ & 5 & $2^{13 .} 6^{6}$ & $30^{13} \cdot 10^{6}$ \\
\hline & $2.27 .27 .21 .3^{\top} 6$ & $24^{1} .24 .50 .37 .30$ & ${ }^{\top} 10^{\top}$ & $2^{12 \cdot} \cdot 6^{5}$ & $30^{12} \cdot 10^{5}$ \\
\hline & $24.34 .33 .3^{\Gamma} 6^{1}$ & $2 .{ }^{\star} 26.29 .{ }^{\star} 3.4^{\top} 5^{\top}$ & ${ }^{\top} 10^{\top}$ & $2^{12 \cdot} \cdot 6^{4}$ & $30^{12} \cdot 10^{4}$ \\
\hline \multirow[t]{5}{*}{5} & $4.5 .^{\top} 45.3^{1} 6$ & 14.38.54.22.30 & 10 & $2^{12} \cdot 6^{3}$ & $30^{12} \cdot 10^{3}$ \\
\hline & 40.57 .36 & 1.27 .53 .26 .15 & 10 & $2^{12 .} 6^{2}$ & $30^{12} \cdot 10^{2}$ \\
\hline & 6.49 .36 & $8.4^{\top} 7^{1} \cdot 20.37 .30$ & 10 & $2^{12} \cdot 6$ & $30^{12} \cdot 10$ \\
\hline & 1.8 .16 * & $52.4^{\Gamma} 4^{1} \cdot 3.4^{\Gamma} 5^{1}$ & 30 & $2^{12}$ & $30^{12}$ \\
\hline & 34.8 & 1.45.28.7.30 & ${ }^{\ulcorner} 30^{1}$ & $2^{11}$ & $30^{11}$ \\
\hline \multirow[t]{5}{*}{10} & 17.4 & $3.30 .56 .1^{\top} 5^{1}$ & $30 \ll 30 »$ & $2^{10}$ & $30^{10}$ \\
\hline & 8.32 & ${ }^{\ulcorner} 77^{1} .1 .^{\top} 52.30^{\top}$ & 30 & $2^{9}$ & $30^{9}$ \\
\hline & 4.16 & 14.3 .45 & 30 & $2^{8}$ & $30^{8}$ \\
\hline & 2.8 & 28.7.30 & 30 & $2^{7}$ & $30^{7}$ \\
\hline & 1.4 & 56.15 & 30 & $2^{6}$ & $30^{6}$ \\
\hline \multirow[t]{3}{*}{15} & 32 & 1.52 .30 & 30 & $2^{5}$ & $30^{5}$ \\
\hline & 16 & 3.45 & 30 & $2^{4}$ & $30^{4}$ \\
\hline & ${ }^{\ulcorner} 8^{1}$ & 7.30 & 30 & $2^{3}$ & $30^{3}$ \\
\hline \multicolumn{6}{|c|}{ Upper Edge } \\
\hline & $r_{4}$ & 15 & $30^{1}$ & $2^{2}$ & $30^{2}$ \\
\hline & 2 & $\sqrt{30}$ & $30^{1}$ & 2 & 30 \\
\hline 20 & 1 & 1 & «30» & 1 & 1 \\
\hline
\end{tabular}



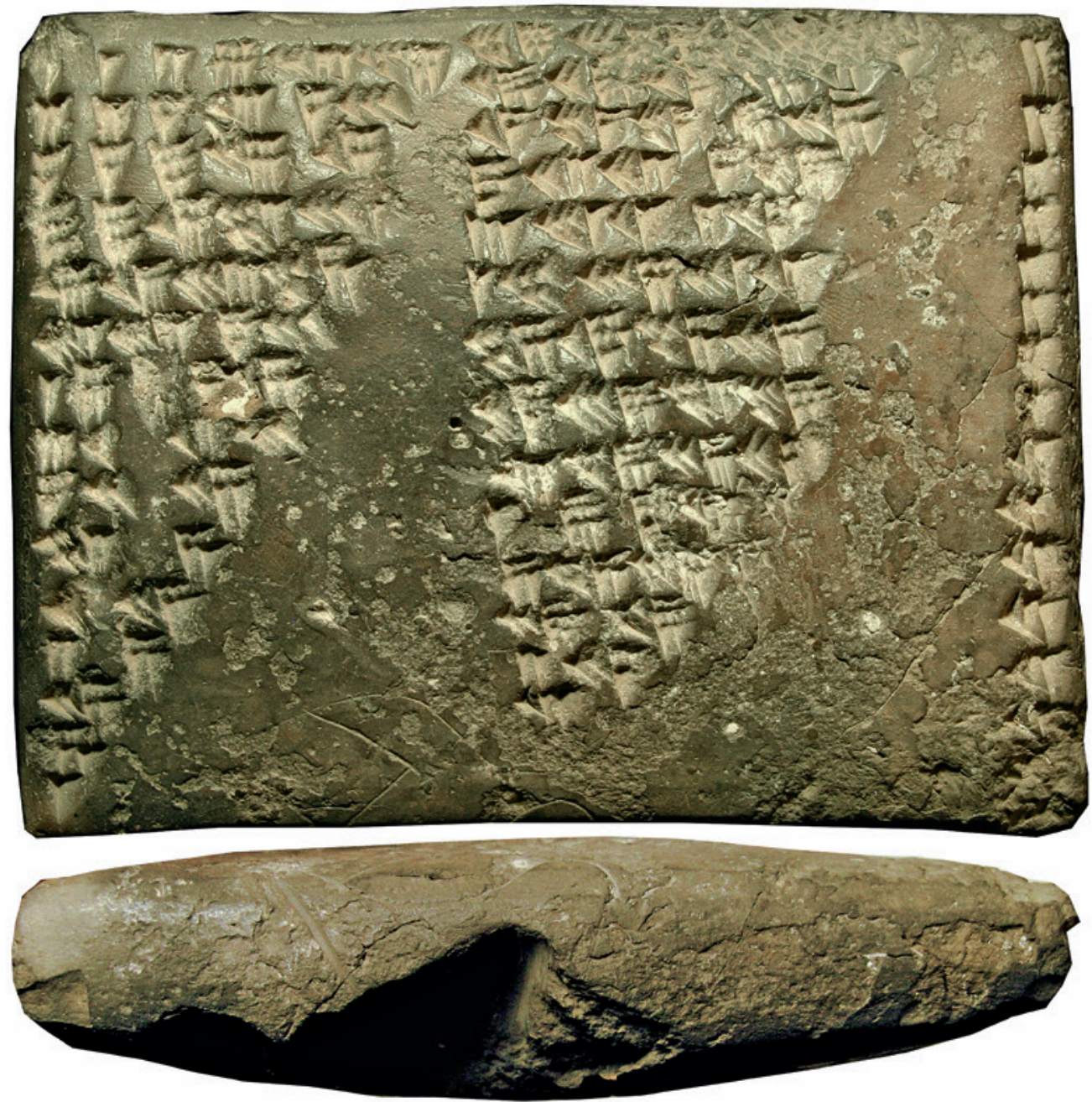

Fig. 1a: BM 46550: obverse (photograph M. Ossendrijver) and lower edge (photograph J. C. Fincke) 

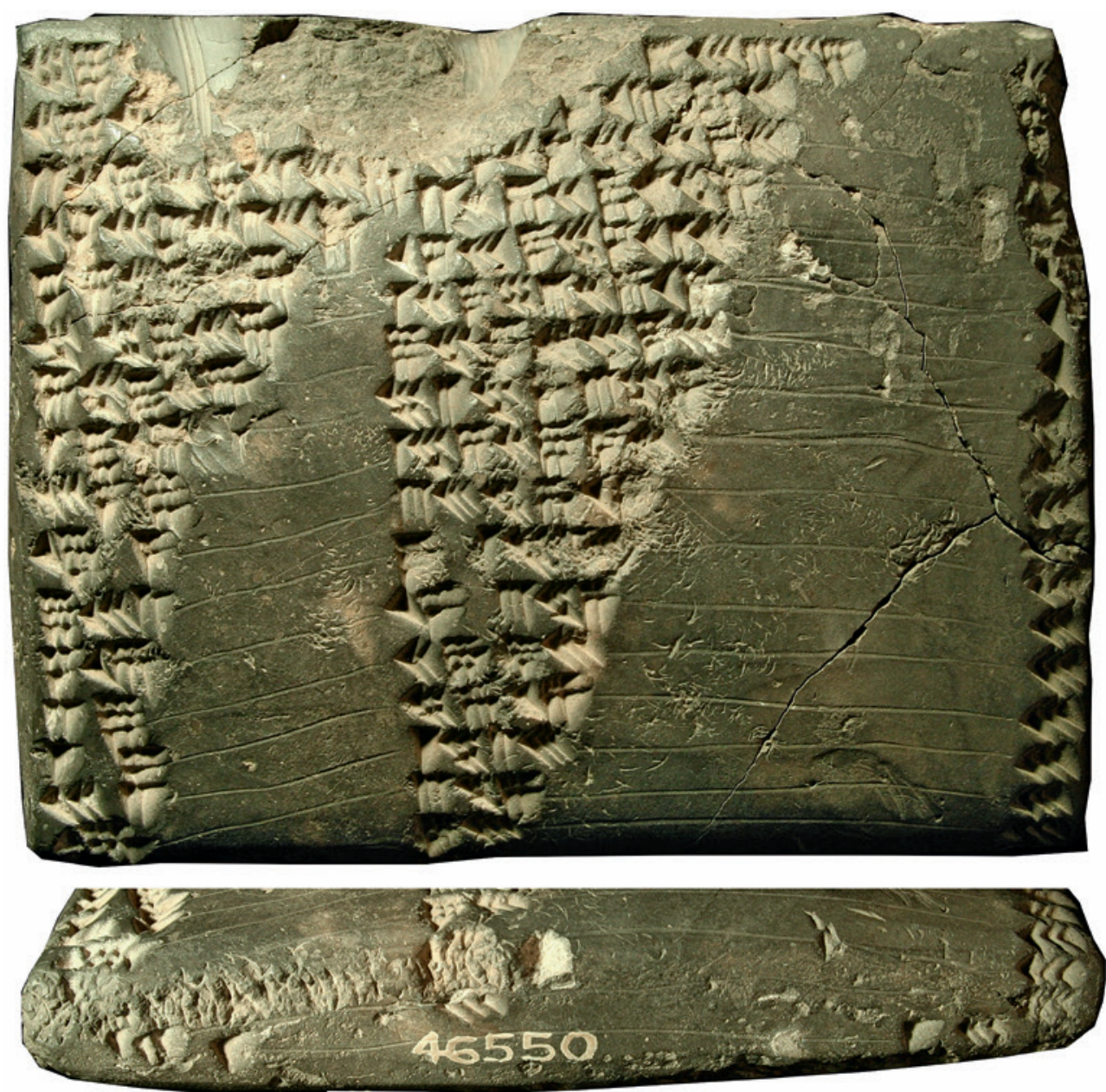

Fig. 1b: BM 46550: reverse and upper edge (photograph M. Ossendrijver) 


\section{BM 46550}

\section{Obverse}

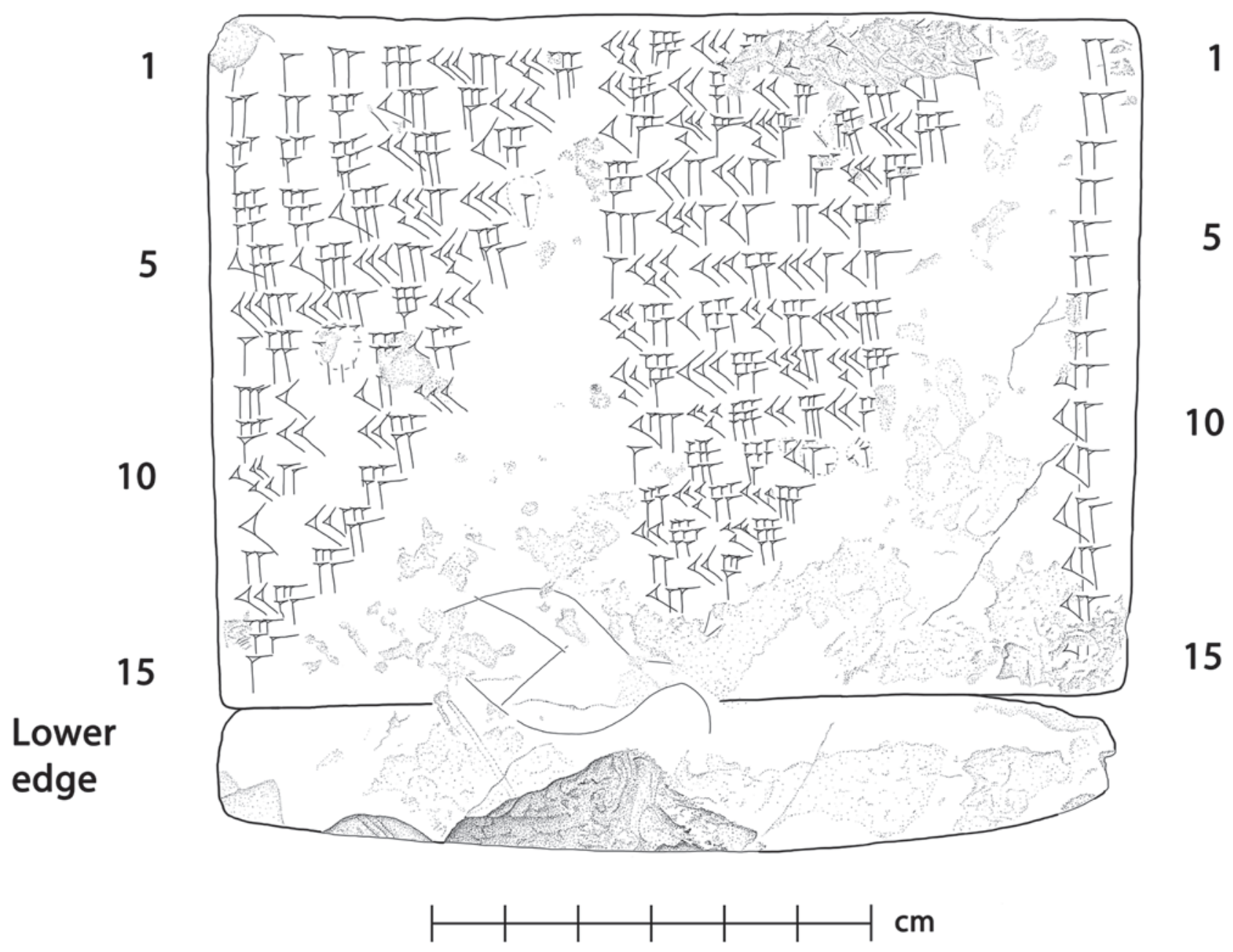

Fig. 2a: BM 46550: copy of the obverse (J. C. Fincke) 


\section{BM 46550}

\section{Reverse}

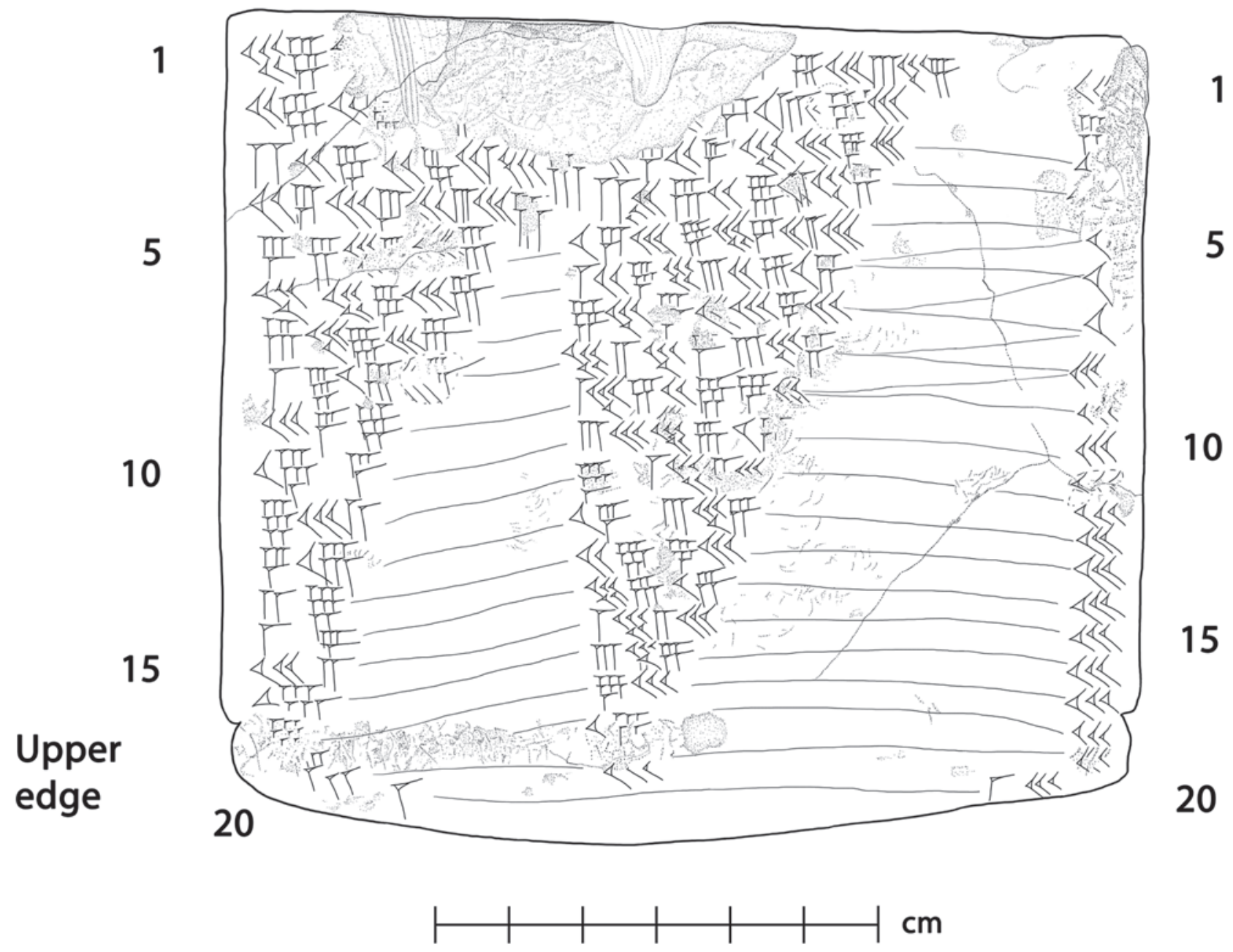

Fig. 2b: BM 46550: copy of the reverse (J. C. Fincke) 


\title{
Line by line commentary
}

\author{
Obverse \\ i 2 9: Here and everywhere else on the tablet the scribe used the pre-Seleucid version of the numeral 9, which \\ consists of 9 vertical wedges arranged in three rows. \\ 2.2.4.13.4.30: One expects 2.2.4.13.7.30. This error was not passed on to the next line. \\ i $4 \quad *$ : The 30 is followed by a partly erased sign of which one vertical wedge can still be seen. \\ i 632 : This is what one expects, but faint traces of a third vertical wedge (33) are visible. \\ i $7 \quad{ }^{*}$ : Between the 5 and the 6 a partly erased sign is visible, perhaps an 8. \\ i 8 3.10.12.30: One expects 2.10.12.30. This error was not passed on to the next line. \\ i 14 5: Clearly written after the partly overlapping 20 in the line above it (13), i.e. col. i was written from top to \\ bottom. \\ ii $8 \quad \star 27.38 .52 .48$ : The 20 is written over a partly erased sign, perhaps a 50 . \\ ii 9 5.45: The bottom ends of these signs are written over the top ends of 28.48 in the next line, i.e. col. ii was \\ written from bottom to top. \\ ii $101.9 .7 .1^{\top} 2^{1}$ : The 2 is written over a partly erased sign. \\ ii 132 : The bottom end is written over the top end of the 12 in the next line (14). \\ iii $15 \quad\left[\mathbf{x}^{?}\right]$ : One expects nothing here. \\ Reverse \\ i 8 \\ 1.8.16 *: The 16 is followed by a partly erased sign, perhaps a 30 . \\ ii 2 [2.2]. ${ }^{\top}{ }^{\top} \cdot 13 .{ }^{\star} 7.30$ : The 7 is written over a partly erased sign. \\ ii $42 .{ }^{\star} 26.29 .{ }^{\star} 3.4^{5} 5^{1}$ : The digits 26 and 3 are written over partly erased signs, the 3 probably over a 10. \\ ii 96 : The bottom end is written over the top end of the 12 in the next line, i.e. col. ii was written from bottom \\ to top. \\ ii 146 , 5: The bottom ends are written over the top ends of the 50 and the 30 in the next line, respectively. \\ iii 6 10: The bottom end is written over the top end of the 10 in the next line. \\ iii 7 10: The bottom end is written over the top end of the 30 in the next line. \\ iii 10-11 In between lines 10 and 11 there is a superfluous 30. \\ Upper Edge \\ i 18-20 Due to a lack of space, the numbers 4, 2 and 1 were not vertically aligned but arranged diagonally. \\ ii 18 15: Damaged by a pattern of scratches covering the entire left half of the line (a trace fossil). \\ ii 20 1: Not vertically aligned with the 30 in line 19 as one expects, but written close to the 30 in col. iii. \\ iii 20 30: Superfluous (see the commentary). Presumably a copying error or a result of confusion caused by the \\ crammed writing in col. i, 18-20.
}

\section{Layout and order of writing}

On each side of the tablet there is a numerical table consisting of three columns. In columns $i$ and ii the numbers are of decreasing length and aligned on the left side, resulting in a triangular layout. The numbers in column iii consist of a single digit and are aligned near the right edge of the tablet. On the obverse there are fifteen rows that exactly fill out the tablet's height. The reverse comprises twenty rows, of which the last four were written on the lower edge in a crammed manner. That the reverse was written less carefully than the obverse is also obvious from the sloppy horizontal alignment of the numbers on that side. Presumably in order to correct this, the scribe connected the numbers in each row by shallow horizontal rulings, positioned at roughly half the height of the signs. Since several of the rulings clearly begin or end at some distance from the numbers, they must have been drawn when the numbers had already been written down. Between columns ii and iii several rulings were initially drawn between the wrong numbers (rows 5-9). Apparently after realising his error, the scribe drew another set of rulings, this time between the correct numbers, but without erasing the erroneous rulings. For instance, the number $8.4^{\lceil} 7^{\top} .20 .37 .30$ in rev. ii 7 was initially, and wrongly, connected to the 10 in rev. iii 6 and then, correctly, to the 10 below it (see below). The rather clumsy execution of the reverse suggests that the scribe was not yet fully trained in applying the recipro- 
cal algorithm (see below). No rulings were added on the obverse, presumably because all numbers on that side are neatly aligned in both directions.

On several occasions a cuneiform sign partly overlaps with one in the previous or following row (see the line by line commentary). By examining the order in which they were impressed with the stylus, the direction of writing can sometimes be inferred. It turns out that on both sides of the tablet column i was written from top to bottom but, unusually for a cuneiform text, column ii from bottom to top. For col. iii the direction of writing could not be established beyond doubt; on the obverse it may have been filled downwards, on the reverse perhaps upwards. The downward and upward directions in which cols. i and ii were respectively written are consistent with the order of the mathematical operations underlying this kind of table (see below). Hence the tablet is at least partly the result of an actual computation and not copied from another tablet. However, two isolated errors (obv. i 2, 8) suggest that col. $\mathrm{i}$ on the obverse was not computed on the spot, because these errors do not affect the next rows (see obv. i 3, 9), which they should according to the algorithm. Two possible explanations offer themselves for this anomaly: either col. $\mathrm{i}$ on the obverse was copied from a correct original and the scribe made two copying errors, or this column was correctly computed on the spot and the error came about as an isolated slip of the stylus. The former explanation seems more probable and is supported by the nature of the errors: as expected for a copying error, the intended signs are similar to the ones that were written down (4 instead of 7 and 2 instead of 3). However, even though col. $\mathrm{i}$ on the obverse was copied from another tablet, there are good reasons to believe that col. i on the reverse was computed on the spot. Especially the sloppy layout of the reverse makes it unlikely that this table was copied from another tablet. We therefore conclude that col. i on the obverse was copied from another tablet, while col. ii on the obverse and cols. i and ii on the reverse were computed on the spot.

\section{Sexagesimal place-value notation, reciprocal numbers and regular numbers}

All numbers are written using sexagesimal place-value notation, i.e. each digit corresponds to a power of 60 which decreases in the rightward direction. The tablet does not provide any context for establishing their absolute value. In the transliteration and in the commentary, the floating nature of the Babylonian notation is preserved by separating all digits by a period (.). ${ }^{15}$ This ambiguity can be viewed as a productive feature that was exploited by the Babylonian scribes. The purpose of this type of table was to compute reciprocal numbers. In accordance with a commonly used convention, the reciprocal of a number $s$ is denoted by $\bar{s}$, i.e. $\bar{s}=1 / s$. Reciprocal numbers feature prominently in Babylonian mathematics because divisions were usually carried out as multiplications by a reciprocal number. For instance, in order to divide by 3 , a Babylonian would multiply by $\overline{3}=0 ; 20$, which was written as 20. It is also useful to introduce the modern notion of regular numbers. ${ }^{16} \mathrm{~A}$ number is called regular if its reciprocal can be expressed as a terminating sequence of digits. Divisions by irregular numbers were avoided, because the resulting reciprocal number does not terminate. From elementary considerations it follows that a sexagesimal number is regular if and only if it contains no other prime factors besides 2, 3 and 5, which are the prime factors contained in $60(=22 \cdot 3 \cdot 5) .{ }^{17}$ Any regular sexagesimal number can therefore be written as the product of powers of 2, 3

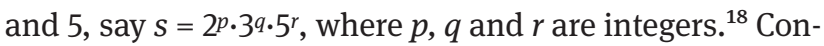
versely, a sexagesimal number is irregular if it cannot be expressed in this manner - for instance, 7. If one knows how many powers of 2, 3 and 5 (i.e. $p, q$ and $r$ ) are contained in $s$, then its reciprocal can be computed from the reciprocals of 2,3 and 5 as $\bar{s}=(0 ; 30)^{p} \cdot(0 ; 20)^{q \cdot} \cdot(0 ; 12)^{r}$, where $0 ; 30=\overline{2}, 0 ; 20=\overline{3}$ and $0 ; 12=\overline{5}$. In the Babylonian floating notation these reciprocals reduce to 30,20 and 12 , respectively, and $\bar{s}$ to $30^{p} \cdot 20 q \cdot 12^{r}$.

15 Furthermore, initial and final vanishing digits (0) are never written. From the fifth century BCE onwards, a sign consisting of two small vertically aligned winkelhaken was used for indicating vanishing intermediate digits in numbers such as 1.0.1. Since the present tablet does not contain any numbers with intermediate zeros, we cannot use the absence of this sign for dating the tablet.

16 The terms "regular number" and "irregular number" are used in publications about Babylonian mathematics at least since the 1930s (see, e.g., Neugebauer 1935, 4), but they are not part of the nomenclature of modern number theory.

17 Analogously, a number is regular in the decimal system if and only if it contains no other factors besides 2 and 5 , the prime factors of 10. Hence regular numbers are more sparse in the decimal system than in the sexagesimal system. For instance, 3 is irregular in the decimal system $(\overline{3}=0.33333 \ldots)$, but regular in the sexagesimal system $(\overline{3}=0 ; 20)$.

18 Note that some combinations of $p, q$ and $r$ result in the same sequence of digits. This is because a change from $(p, q, r)$ to $(p+2 n, q+n$, $r+n$ ), where $n$ is an integer, amounts to a multiplication by $60^{n}$. 


\section{Mathematical commentary}

With these preparations, the purpose, layout and computation of BM 46550 are easily explained. Each side contains, in tabular form, an algorithm for computing the reciprocal of an initial number which is written in the upper left corner (col. i, row 1). In a first computation that is executed in col. $\mathrm{i}$, all elementary factors, say $f$, that are contained in $s$ are identified. One minor modification to be noted is that these factors need not be 2,3 or 5 . Other factors that are products of 2, 3 and 5 can also be used, e.g., 6, 12 or 30. This reflects the different, mathematically equivalent ways in which a regular number can be factorized. The elimination of all factors $f$ contained in $s$ is achieved by multiplying $s$ by the reciprocals of these factors, $\bar{f}$. A notable feature of BM 46550 is that the values of $\bar{f}$ are tabulated in their own column (iii). Setting out from row 1 , the product $s \cdot \bar{f}$ was written in the next row. On the obverse, 1.1.2.6.33.45 (col. i, row 1) was multiplied by $\bar{f}=2$ and the product, 2.2.4.13.7.30, was written in row 2 . By doing so, one factor $f=\overline{2}=30$ was eliminated from $s$. The same factor 2 was used eight times, so that in total eight powers of 30 were cancelled from $s$ (see the explanatory column s). The scribe then continued with $\bar{f}=12$, which he applied five times, thereby removing five powers of $\overline{12}=5$, until 1 was reached in the last row. In a second step the same factors $\bar{f}$ were multiplied in the upward direction in col. ii, each factor being repeated as many times as it occurred in col. i, setting out from $1 .{ }^{19}$ The resulting numbers in col. ii are the reciprocals of the numbers in col. i. In particular, the final result, 58.58.56.38.24 (ii 1), is the reciprocal of the initial number 1.1.2.6.33.45 (i 1).

Another notable feature of BM 46550 is that the reciprocal algorithm is applied twice in succession, with the outcome of the obverse, 58.58.56.38.24 (obv. ii 1), serving as input for the reverse. The final result, 1.1.2.6.33.45 (rev. ii 1), coincides with the initial number on the obverse, 1.1.2.6.33.45, as it should. ${ }^{20}$ We will discuss the possible reason for

19 To be precise, the next value of $\bar{s}$ to be written in col. ii is obtained by multiplying the value of $\bar{f}$ in that same row by the number in col. ii in the row below it.

20 As mentioned, cuneiform sexagesimal numbers do not have a unique absolute representation. In the explanatory columns, $s$ and $\bar{s}$, 1.1.2.6.33.45 is represented in two different ways. On the obverse as $5^{6.30^{8}}$, which reflects the six factors of 5 and the eight factors of 30 that were removed in the downward direction; on the reverse as $30^{14} \cdot 10^{6}$, which reflects, effectively, the 14 factors of 30 and the six factors of 10 that were multiplied upwards in col. ii. Alternative representations could be obtained by multiplying with any power of 60 . Note that $30^{14} \cdot 10^{6}=60^{6} \cdot 5^{6} \cdot 30^{8}$, so that both representations indeed correspond to the same cuneiform sexagesimal number. this double execution of the reciprocal algorithm further below. The way in which the scribe computed both reciprocal numbers is revealing. After finishing the obverse he could have exploited his knowledge of the factors $\bar{f}$ (eight times $\bar{f}=2$ and six times $\bar{f}=12$ ) by adopting their reciprocals, i.e. 30 and 5 , as the values of $\bar{f}$ on the reverse. In that case the reverse would have contained 15 rows like the obverse, but he did not use that shortcut. Instead, the reverse was executed with an independent set of factors, once again chosen on the basis of the final digit of the numbers in col. i. The scribe began with $\bar{f}=30$, which he multiplied with 58.58.56.38.24 to yield 29.29.28.19.12, thereby removing one power of 2 from $s$. From there he proceeded with $\bar{f}=5$, removing one power of 12 (i.e. one power of 2 and one power of 6), then five times $\bar{f}=10$, removing five powers of 6 , and twelve times $\bar{f}=30$, removing as many powers of 2 . At this point the factorization came to an end. After reaching the lower edge of the tablet (i 18), the scribe continued in a crammed manner. This appears to have caused some confusion, because the final 30 in col. iii is superfluous. Nevertheless the scribe correctly multiplied all factors $\bar{f}$ in the upward direction in col. ii, omitting the superfluous 30. In this manner the correct result, 1.1.2.6.33.45, was obtained in ii 1.

Perhaps the main difficulty for a Babylonian scribe wishing to compute the reciprocal of a number was to choose appropriate factors $\bar{f}$ that, upon multiplication with this number, yield successively smaller numbers, until 1 is reached. Investigations of several tablets with reciprocal algorithms have revealed that the choice of $\bar{f}$ was determined by the final one or two digits of the number (Friberg 1999, 148-158; Proust 2012, 399-402). Currently not all of the rules by which the Babylonian scribes chose $\bar{f}$ are known, neither for the Old Babylonian tablets, nor for the later ones. However, it is reasonably clear that a final digit 30 should have prompted $\bar{f}=\overline{30}=2$. Similarly, a final digit 5 or 25 should have prompted $\bar{f}=\overline{5}=12$, a final digit $2,4,8$, 16 or $32 \bar{f}=\overline{2}=30$, and a final digit $12,24,36$, or $48 \bar{f}=\overline{2}=5$. Turning to BM 46550, the digits 15, 30 and 45 (obv. i 1-8) appear to have prompted $\bar{f}=2$. The digits 5 and 25 (obv. i 9-14) prompted $\bar{f}=12$, as expected. On the reverse the digit 24 (i 1) prompted $\bar{f}=30$ instead of the expected 5 . The digit 12 (i 2) prompted $\bar{f}=5$, as expected. The digit 36 (i 3-7) unexpectedly prompted $\bar{f}=10$, and the digits $2,4,8,16$ and 32 (i 8-19) prompted $\bar{f}=30$, as expected. Note that an unexpected choice of a factor $\bar{f}$ does not imply that the final result will be wrong. However, it will take a larger number of steps to find the reciprocal of the initial number, resulting in a longer table. While the present scribe was ultimately fully succesful in his efforts to compute the recip- 
rocals, some of the factors suggest that he did not have much experience with the algorithm.

\section{Comparison with Old Babylonian and Late Babylonian parallels}

The closest Late Babylonian parallels of our tablet are SpTU 4, 176 (Friberg 1999) and SpTU 5, 316 (Friberg 2007, 453). Both were excavated in Uruk and may have belonged to the library of the Šangû-Ninurta family, which dates to about $415 \pm 30$ BCE (Clancier 2009, 58-59). The former tablet contains eight tables very similar to those on BM 46550, except that they lack a col. iii with the reciprocal factors $\bar{f}$. SpTU 5, 316 contains a single column in which a five-digit sexagesimal number is factorized down to 1 , as in col. i of BM 46550, but it lacks cols. ii and iii. Also to be mentioned here are two Late Babylonian tablets from Babylon partly preserving a single column in which a sexagesimal number with up to 30 digits is factorized down to 1 in the same manner (Ossendrijver 2014, Texts A, B). However, SpTU 5, 316 and the latter two tablets probably lacked a col. ii, so their purpose was not to compute reciprocal numbers. Turning to the Old Babylonian era, at least nineteen tablets preserve similar algorithms for computing reciprocal numbers. ${ }^{21}$ While containing essentially the same type of numerical data as BM 46550, their layout is different. First, on the Old Babylonian tablets col. i terminates whenever a number is reached whose reciprocal can be found in the Old Babylonian standard table of reciprocals. ${ }^{22}$ Second, the reciprocal factors $\bar{f}$ are written in col. ii. Third, the successive multiplications with the factors $\bar{f}$ are not written upwards in a column that runs parallel to cols. $\mathrm{i}$ and ii, but downwards in a column that is positioned below cols. i and ii. However, BM 46550 is the only extant Neo- or Late Babylonian example of a reciprocal algorithm that exhibits two features thus far attested only on the Old Babylonian tablets: first, it includes a column with reciprocal factors $(\bar{f})$ and, second, the algorithm on the reverse is the inverse of the algorithm on the obverse (see below).

With regard to the initial number of BM 46550, 1.1.2.6.33.45, it can hardly be a coincidence that this number and its

21 The pioneering study of these tablets is Sachs (1947). For a detailed study of the underlying algorithm see Proust (2012). For a list of currently known tablets see Proust (2012, 405, footnote 37; 406).

22 This table was part of the Old Babylonian school curriculum and is attested in numerous copies; see Neugebauer (1935, 8-14); Proust (2012, 390). reciprocal form the second entry in the Late Babylonian standard table of reciprocals, which contains 100 regular numbers with initial digit 1 and their reciprocals. ${ }^{23}$ Thus far 15 fragments preserving a part of this table have been identified, probably all from Seleucid Babylon. As pointed out by Friberg $(1999,155)$, the eight algorithms contained on the Achaemenid tablet SpTU 4, 176 are likewise concerned with the computation of reciprocal numbers from the standard table. It is theoretically possible that BM 46550 and SpTU 4, 176 preserve the original computations of reciprocal numbers that were subsequently compiled in that table. ${ }^{24}$ However, it seems more likely that the standard table already existed when BM 46550 and SpTU 4, 176 were written. Perhaps BM 46550 and SpTU 4, 176 are exercises in which the reciprocal algorithm was practiced using entries from that table.

As mentioned earlier, a notable feature of BM 46550 is that the outcome of the computation on the obverse, 58.58.56.38.24, serves as input for an independent computation of its reciprocal, which yields the initial number of the obverse, 1.1.2.6.33.4. By contrast, all the algorithms on SpTU 4, 176 were executed in one direction only. However, the same arrangement, with the reciprocal algorithm executed twice in succession, each time using a different set of factors $\bar{f}$, is encountered in the Old Babylonian tablet CBS 1215 (Sachs 1947, 230; Robson 2000, 23). As argued by Proust (2012, 397-399), this double execution of the reciprocal algorithm may have served a didactical purpose. In particular, it can be interpreted as a strong verification of the reciprocal algorithm. The scribe could have verified the computations on the obverse by multiplying 1.1.2.6.33.45 by 58.58.56.38.24, which should yield 1 or, alternatively, by inverting the particular sequence of steps by which the reciprocal of 1.1.2.6.33.45 was computed. Instead of these straightforward methods of verification, the scribe executed the reciprocal algorithm for a second time and independently from the steps taken on the obverse. BM 46550 represents the first evidence that this Old Babylonian practice continued to exist in the Neo- or Late Babylonian era.

Acknowledgements:The Trustees of the British Museum are acknowledged for permission to study and publish the tablet and the photographs. We thank C. B. F. Walker

23 For a reconstruction of the complete table see Britton (1991-3, 76f.) and Friberg (2007, 461-464). Only one of the fifteen known fragments preserves entry Nr. 2 (Ossendrijver 2014, Text C).

24 SpTU 4, 176 computes the reciprocals of eight reciprocal numbers $(\bar{s})$ taken from col. ii of the Late Babylonian standard table. This yields the corresponding principle numbers $(s)$, which are tabulated in col. $i$ of that table. 
for making available his transliteration of the tablet. We thank the staff of the Middle East Department of the British Museum for their support. Jeanette Fincke acknowledges support of the M4Human fellowship granted by the Gerda Henkel-Stiftung in co-finance with the European Commission for her project "Solar Eclipses in their Ancient Near Eastern Perception”, which enabled her to search the cuneiform collections of the British Museum. Mathieu Ossendrijver acknowledges support by the Excellence Cluster TOPOI, DFG grant EXC 264.

\section{Abbreviations}

[not listed in RIA]

CT 56 and 57 Th. G. Pinches, Cuneiform texts from Babylonian records in the British Museum part 55 and 56: Neo-Babylonian and Achaemenid economic texts (London 1982)

VBoT A. Götze, Verstreute Boghazköi-Texte (Marburg 1930)

\section{Bibliography}

Biggs, R. D. (1966): The Abū Șalābīkh tablets. A preliminary survey, JCS 20, 73-88

Biggs, R. D. (1974): Inscriptions from Tell Abū Șalābīkh. OIP 99. Chicago/London

Britton, J. P. (1991-3): A table of 4th powers and related texts from Seleucid Babylon, JCS 43-45, 71-78

Clancier, Ph. (2009): Les bibliothèques en Babylonie dans la deuxième moitié du ler millénaire av. J.-C. AOAT 363. Münster

Deimel, A. (1923): Die Inschriften von Fara II: Schultexte aus Fara. WVDOG 43. Leipzig
Finkel, I. L. (2011): Drawings on tablets, Scienze dell'Antichità 17, 337-344

Friberg, J. (1999): A Late Babylonian factorization algorithm for the computation of reciprocals of many-place regular sexagesimal numbers, BaM 30, 139-163. [Erratum: J. Friberg (2000): Corrigendum zum Beitrag Friberg in BaM 30, 1999, BaM 31, 447-448]

Friberg, J. (2005): Mathematical texts, in: I. Spar/W. G. Lambert (eds.), Cuneiform texts in the Metropolitan Museum of Art II: Literary and scholastic texts of the first millennium B. C. New York, 288-314

Friberg, J. (2007): A remarkable collection of Babylonian mathematical texts. Manuscripts in the Schøyen Collection, Cuneiform texts 1. New York

Gesche, P. (2001): Schulunterricht in Babylonien im ersten Jahrtausend v. Chr. AOAT 275. Münster

Leichty, E. (1986): Catalogue of the Babylonian tablets in the British Museum, vol. VI: Tablets from Sippar 1. London

Ludwig, M.-C. (2009): Literarische Texte aus Ur. Kollationen und Kommentare zu UET 6/1-2. UAVA 9. Berlin/New York

Neugebauer, O. (1935): Mathematische Keilschrifttexte I. Berlin

Ossendrijver, M. (2012): Babylonian mathematical astronomy. Procedure texts. New York

Ossendrijver, M. (2014): The powers of 9 and related mathematical tables from Babylon, JCS 66, 149-165

Pedersén, O. (2005): Archive und Bibliotheken in Babylon. Die Tontafeln der Grabung Robert Koldeweys 1899-1917. ADOG 25. Saarbrücken

Proust, C. (2012): Interpretation of reverse algorithms in several Mesopotamian texts, in: K. Chemla (ed.), The history of mathematical proof in ancient traditions. Cambridge, 384-422

Robson, E. (2000): Mathematical cuneiform tablets in Philadelphia, Part 1: Problems and calculations, Sciamus 1, 11-48

Sachs, A. J. (1947): Babylonian mathematical texts I: Reciprocals of regular sexagesimal numbers, JCS 1, 219-240

Weidner, E. F. (1967): Gestirn-Darstellungen auf babylonischen Tontafeln. Wien

Zawadzki, S./M. Jursa (2001): Šamaš-tirri-kușur, a smith manufacturing weapons in the Ebabbar temple at Sippar, WZKM 91, 347-363 